\title{
Digoxin inhibits PDGF-BB-induced VSMC proliferation and migration through an increase in ILK signaling and attenuates neointima formation following carotid injury
}

\author{
GAOLIANG YAN $^{1}$, QINGJIE WANG $^{1}$, SHENGDA HU ${ }^{1}$, DONG WANG $^{1}$, YONG QIAO $^{1}$, \\ GENSHAN MA ${ }^{1}$, CHENGCHUN TANG ${ }^{1}$ and YUCHUN GU ${ }^{2}$ \\ ${ }^{1}$ Department of Cardiology, Zhongda Hospital of Southeast University Medical School, Nanjing, Jiangsu 210009; \\ ${ }^{2}$ Institute of Molecular Medicine (IMM), Peking University, Beijing 100190, P.R. China
}

Received November 27, 2014; Accepted July 31, 2015

DOI: $10.3892 / \mathrm{ijmm} .2015 .2320$

\begin{abstract}
The increased proliferation and migration of vascular smooth muscle cells (VSMCs) are key events in the development of artery restenosis following percutaneous coronary intervention. Digoxin has long been used in the treatment of heart failure and has been shown to inhibit the proliferation of cancer cells through multiple pathways. However, the potential role of digoxin in the regulation of VSMC proliferation and migration and its effectiveness in the treatment of cardiovascular diseases, such as restenosis, remains unexplored. In the present study, we demonstrate that digoxin-induced growth inhibition is associated with the downregulation of CDK activation and the restoration of $\mathrm{p} 27 \mathrm{Kip} 1$ levels in platelet-derived growth factor (PDGF)-stimulated VSMCs. In addition, we found that digoxin restored the PDGF-BB-induced inhibition of integrin linked kinase (ILK) expression and prevented the PDGF-BBinduced activation of glycogen synthase kinase (GSK)-3 $\beta$. Furthermore, digoxin inhibited adhesion molecule and extracellular matrix relative protein expression. Finally, we found that digoxin significantly inhibited neointima formation, accompanied by a decrease in cell proliferation following vascular injury in rats. These effects of digoxin were shown to be mediated, at least in part, through an increase in ILK/Akt signaling and a decrease in GSK-3 $\beta$ signaling in PDGF-BBstimulated VSMCs. In conclusion, our data demonstrate that
\end{abstract}

Correspondence to: Dr Chengchun Tang, Department of Cardiology, Zhongda Hospital of Southeast University Medical School, 87 Dingjiaoqiao, Nanjing, Jiangsu 210009, P.R. China

E-mail: tangchengchun@medmail.com.cn

Dr Yuchun Gu, Institute of Molecular Medicine (IMM), Peking University, 11 Zhongguancun Beiyitiao, Beijing 100190, P.R. China E-mail:ycgu@pku.edu.cn

Key words: digoxin, vascular smooth muscle cell, proliferation, migration, integrin linked kinase, glycogen synthase kinase-3 $\beta$, neointima formation digoxin exerts an inhibitory effect on the PDGF-BB-induced proliferation, migration and phenotypic modulation of VSMCs, and prevents neointima formation in rats. These observations indicate the potential therapeutic application of digoxin in the treatment of cardiovascular diseases, such as restenosis.

\section{Introduction}

During the switching from a differentiated/contractile to a dedifferentiated/synthetic phenotype, the increased proliferation and migration of vascular smooth muscle cells (VSMCs) are key events in the development of artery restenosis following percutaneous coronary intervention (1-3). All these events may be induced by cytokines, such as platelet-derived growth factor BB (PDGF-BB) (4). PDGF-BB initiates a multitude of biological effects through the activation of intracellular signal transduction pathways that contribute to VSMC phenotypic modulation, proliferation, migration and collagen synthesis. The importance of PDGF-BB in the development of neointima formation has been established in models of arterial injury (5). Therefore, the inhibition of PDGF-stimulated VSMC proliferation, migration and phenotypic modulation may represent an important point of therapeutic intervention in restenosis following angioplasty.

Digoxin has been used as an effective therapy to treat patients with congestive heart failure (CHF) for decades $(6,7)$. Previous studies have highlighted a new aspect of the biology of cardiac glycosides as versatile signal transducers $(8,9)$ in that they control the transcription of specific genes (10). Cardiac glycosides (endogenous and exogenous) have been implicated in the regulation of a number of important physiological and pathological states (11-13). Furthermore, unexpected results from epidemiological studies describing significantly lower mortality rates of patients with cancer receiving cardiac glycosides have sparked new interest into the anticancer properties of these drugs. Subsequent in vitro and in vivo studies verified these initial observations (14-16). Another study demonstrated that digoxin inhibited the growth of neuroblastoma tumor xenografts in mice and angiogenesis in chick chorioallantoic membrane assays (17). In addition, in a previous study, Yoshida et al (18) demonstrated that digoxin suppressed 
retinal and choroidal neovascularization, which blocks several proangiogenic pathways. However, the role of digoxin in regulating VSMC activation is not yet clearly understood. Although digoxin has been found to attenuate the development of right ventricle hypertrophy and prevent pulmonary vascular remodeling, as well as the increase in pulmonary artery smooth muscle cell $\left[\mathrm{Ca}^{2+}\right] \mathrm{i}$ and $\mathrm{pH}$ levels that occur in mice exposed to chronic hypoxia (19), little is known about the role of digoxin in regulating aortic VSMC proliferation and migration and its effectiveness in the prevention of restenosis.

In this study, we demonstrate that digoxin exerts an inhibitory effect on the PDGF-BB-induced proliferation, migration and phenotypic modulation of VSMCs, and prevents neointima formation induced by balloon injury. We also demonstrate that the digoxin-induced growth inhibition is associated with the downregulation of CDK activation and the restoration of p27Kip1 levels in PDGF-stimulated VSMCs. This effect of digoxin is mediated, at least in part, through an increase in integrin linked kinase (ILK)/Akt signaling and a decrease in glycogen synthase kinase (GSK)-3 $\beta$ signaling in PDGF-BBstimulated VSMCs.

\section{Materials and methods}

Ethics statement. Animal experiments were carried out in accordance with the Guide for the Care and Use of Laboratory Animals published by the US National Institutes of Health (DHWE publication no. 96-01, revised in 2002) and was approved by the Ethics Review Board for Animal Studies of Institute of Southeast University, Nanjing, China.

Reagents. Recombinant human PDGF-BB, trypan blue reagent, the phosphoinositide 3-kinase (PI3K) specific inhibitor, LY294002, the GSK-3 $\beta$ antagonist, SB415286, and cell proliferation reagent 3-(4,5-dimethylthiazol-2-yl)-2,5-diphenyltetrazolium bromide (MTT) were purchased from Sigma, St. Louis, MO, USA. The proliferating cell nuclear antigen (PCNA) antibody was purchased from Cell Signaling Technology (Product no. 2586s). Trypsin-ethylenediaminetetraacetic acid (EDTA) (0.25\%), Dulbecco's modified Eagle's medium/F12 (DMEM/F12) and fetal bovine serum (FBS) were from PromoCell (Heidelberg, Germany). The digoxin injection was acquired from Minsheng Pharmaceutical Group Co., Ltd. (Hangzhou, China). Digoxin was purchased from J\&K Scientific Ltd. (Beijing, China) and dissolved in dimethyl sulfoxide (DMSO), and the concentration of DMSO was $<0.8 \%$ in the control and drug-containing medium.

Cell proliferation assay. Proliferation was measured using cell counts and MTT assay, as previously described. For cell counts: VSMCs were seeded onto 96 -well plates $\left(4 \times 10^{3}\right.$ cells/well) and treated with various concentrations of digoxin for $24 \mathrm{~h}$ prior to stimulation with or without PDGF-BB $(25 \mu \mathrm{g} / \mathrm{l})$. The cells were then trypsinized with $0.1 \%$ trypsin-EDTA and counted using a hemocytometer under a microscope. For MTT assay: briefly, the cells at $60 \%$ confluency were plated in a $96-$ well microplate, and growth was arrested by serum deprivation for $24 \mathrm{~h}$. The cells were then treated with PDGF-BB $(25 \mu \mathrm{g} / \mathrm{l})$ in the presence/absence of digoxin for $24 \mathrm{~h}$ and loaded with MTT for the last $3 \mathrm{~h}$. Subsequently, the cells were dissolved by DMSO, and the color intensity was read at $540 \mathrm{~nm}$.
Evaluation of cell viability. Trypan blue exclusion was used to determine the viability of the VSMCs and human umbilical vein endothelial cells (HUVECs; purchased from PromoCell, Heidelberg, Germany; Cat. no. C-12200). Following treatment with various concentrations of digoxin for 24 or $48 \mathrm{~h}$, the VSMCs or HUVECs were trypsinized and incubated with $0.4 \%$ trypan blue dye. Cell viability was assessed by the automated determination of the percentage of cells that were able to exclude trypan blue using a Countess Automated Cell Counter (Invitrogen).

Assays of cell cycle progression. Cell cycle progression was assessed using propidium iodide (PI) staining with fluorescence-activated cell sorting (FACS) analysis. Briefly, cells at $70 \%$ confluence were pre-incubated in the presence or absence of digoxin $(100 \mathrm{nM})$ in serum-free medium for 24 hand and then stimulated with PDGF-BB $(25 \mu \mathrm{g} / \mathrm{l})$ for $24 \mathrm{~h}$. The cells were then trypsinized and fixed with ethanol at $4^{\circ} \mathrm{C}$ overnight. The fixed cells were collected by centrifugation $\left(1000 \mathrm{x} \mathrm{g}, 4^{\circ} \mathrm{C}\right)$, washed twice in phosphate-buffered saline (PBS) and incubated with $600 \mu \mathrm{l}$ PI staining buffer $(20 \mathrm{mg} / \mathrm{ml} \mathrm{PI}$ and $50 \mathrm{mg} /$ $\mathrm{ml}$ RNaseA), and then analyzed with FACS. The cell cycle distributions were analyzed using MultiCycle AV software (Phoenix Flow Systems, San Diego, CA, USA).

Western blot analysis. The VSMCs were cultured in a 9-cm diameter dish, grown to $70-80 \%$ confluency, and then starved in serum-free medium for $24 \mathrm{~h}$. The cells were lysed in radioimmunoprecipitation assay (RIPA) buffer with protease and phosphatase cocktails. Equal amounts of protein (60-100 $\mu \mathrm{g}$ ) were separated by $10 \%$ sodium dodecyl sulfate-polyacrylamide gel electrophoresis (SDS-PAGE) and electrotransferred onto PVDF membranes (Millipore, Billerica, MA, USA). The membranes were blocked, and then incubated with various antibodies overnight, such as anti-CDK4 (Cat. no. SC23896, 1:500), anti-CDK6 (Cat. no. SC53638, 1:500), anti-p27Kip1 (Cat. no. SC1641, 1:500) (all from Santa Cruz Biotechnology, Inc., Santa Cruz, CA, USA), anti-SM22a (Cat. no. A5228, 1:1,000), anti-calponin (Cat. no. C2687, 1:1,000), anti-smooth muscle (SM) $\alpha$-actin (Cat. no. A2172, 1:1,000) (all from Sigma), anti-phosphoc-Jun NH2-terminal kinase (p-JNK; Tyr183/185; Cat. no. 5135, 1:1,000), anti-JNK (Cat. no. 9258 1:1,000), anti-p38 mitogenactivated protein kinase (MAPK; Cat. no. 9228, 1:1,000), anti-phospho-p38 MAPK (Thr180/Tyr182; Cat. no. 4092, 1:1,000; p-MAPK), anti-extracellular signal-regulated kinase (ERK)1/2 (Cat. no. 4696, 1:1,000), anti-phospho-ERK1/2 (p-ERK, Tyr204; Cat. no. 4374, 1:1000), anti-phospho-Akt (p-Akt, S473; Cat. no. 12694, 1:1,000), anti-Akt (Cat. no. 2920, 1:1,000), anti-phospho-GSK-3 $\beta$ (p-GSK-3 $\beta$, S9; Cat. no. 14630, 1:1,000), anti-GSK-3 $\beta$ (Cat. no. 9832, 1:1,000) (all from Cell Signaling Technology), anti-ILK (Cat. no. 61183, 1:1,000; BD Biosciences, Franklin Lakes, NJ, USA), anti-intercellular adhesion molecule-1 (ICAM-1; Cat. no. 4915, 1:500), anti-vascular cell adhesion molecule-1 (VCAM-1; Cat. no. 13662, 1:500) (both from Cell Signaling Technology), anti-matrix metalloproteinase (MMP)-2 (Cat. no. SC13594, 1:500), anti-MMP-9 (Cat. no. SC21733, 1:500) anti-tissue inhibitors of metalloproteinase (TIMP)-1 (Cat. no. SC21734, 1:500), anti-TIMP-2 (Cat. no. SC365671, 1:500) (all from Santa Cruz Biotechnology, Inc.), anti-glyceraldehyde 3-phosphate dehydrogenase (GAPDH; Cat. no. 5174, 
1:2,500) and anti- $\beta$-actin (Cat. no. 8457, 1:2,500) (both from Cell Signaling Technology), and then with the horseradish peroxidaseconjugated secondary antibody (Beijing TDY Biotech Co., Ltd.) $(1: 5,000)$ for $2 \mathrm{~h}$. Specific protein expression levels were normalized to GAPDH or $\beta$-actin for total protein analyses or to total proteins for phosphorylated protein measurements. The blots were analyzed using the ChemiDoc ${ }^{\mathrm{TM}} \mathrm{MP}$ imaging system (BioRad Laboratories, Inc., Hercules, CA, USA). The experiments were replicated a number of times.

VSMC culture and treatment. Primary VSMCs were obtained from the thoracic aortas of male Sprague-Dawley rats weighing between 150 and $180 \mathrm{~g}$ (3 rats per experiment for the VSMCs), and were grown in DMEM/F12 medium containing 10\% FBS, $25 \mathrm{mmol} / 1 \mathrm{HEPES}\left(\mathrm{pH} \mathrm{7.4)}\right.$ at $37^{\circ} \mathrm{C}$ in a humidified atmosphere of $95 \%$ air and $5 \% \mathrm{CO}_{2}$, as previously described (20). The purity of the VSMCs was assessed by cell morphological observations as the characteristic 'hill and valley' growth pattern and positive immunocytochemical staining with a monoclonal antibody against smooth muscle $\alpha$-actin. All the experiments were performed using VSMCs at passages 3-8.

Migration assay. Migration assay was performed using the Transwell system (a $6.5-\mathrm{mm}$ polycarbonate membrane with 8.0- $\mu$ m pores; Corning, Inc., Corning, NY, USA) (20). Cells suspensions $\left(5 \times 10^{4}\right)$, containing fresh serum free medium, were seeded on the upper chamber. PDGF-BB with or without digoxin was added to the bottom chamber as the chemoattractant. The cells were allowed to migrate through the membrane to the lower surface for $6 \mathrm{~h}$. Cells on the upper surface of the membrane that had not migrated were scraped off with cotton swabs, and cells that had migrated to the lower surface were fixed by $3.7 \%$ paraformaldehyde and stained with $0.1 \%$ crystal violet $/ 20 \%$ methanol and counted. The migrated cell numbers were calculated as the number of migrated cells $/ 5$ different random high-power fields (at x200 magnification).

Immunofluorescence staining. Following treatment, the cells were washed with PBS, fixed with $3.7 \%$ paraformaldehyde for $15 \mathrm{~min}$ at room temperature, and then treated with $0.1 \%$ Triton X-100 in PBS for 5 min. After washing, the cells were blocked with $2 \%$ bovine serum albumin (BSA) in PBS for $30 \mathrm{~min}$. The cells were then incubated with primary antibodies for $1 \mathrm{~h}$ at room temperature, washed with PBS, and then incubated with FITC-conjugated secondary antibodies for $1 \mathrm{~h}$ in the dark. Cells were mounted with $90 \%$ glycerol-PBS and examined under a fluorescence microscope (Nikon, Tokyo, Japan).

Balloon injury and morphometric analysis of neointima formation. Balloon denudation of the left common carotid artery of the male Sprague-Dawley rats was performed, as previously described (20). Sprague-Dawley rats $(n=48$, weighing 300-350 g) were anesthetized using chloral hydrate (350 mg/kg, i.p.), and the left common and external carotid arteries were exposed and isolated. A $1.5 \mathrm{~F}$ Fogarty catheter (Edwards Lifesciences, Irvine, CA, USA) was introduced into the common carotid artery through an arteriotomy in the external carotid artery and inflated to 2.0-3.0 atm and withdrawn repeatedly 3 times. The external carotid artery was then ligated, and the blood flow was restored. Following balloon injury, digoxin $(1.0 \mathrm{mg} / \mathrm{kg} /$ day $)$ was intraperitoneal injected for 14 days. The control rats also received a similar volume of distilled water. For preparing the sham-operated rats, the left common carotid artery and external carotid artery were exposed and ligated as above, but the catheter was not inserted into the vessels. The arteries were collected on day 14 after balloon injury, and embedded in paraffin to prepare cross sections. Sections for analysis were taken from the middle part of the injured segment and cut at equally spaced intervals of $2 \mathrm{~mm}$. The prepared sections were cleared with xylene, and hydrated with ethanol. The sections were stained with hematoxylin and eosin or incubated overnight at $4^{\circ} \mathrm{C}$ with primary antibodies (PCNA; 1:200). The incubated sections were treated with biotinylated pan-specific antibody (Vector Laboratories, Burlingame, CA, USA) for $1 \mathrm{~h}$ and incubated in ABC solution (Elite $\mathrm{ABC}$ kit, Vector Laboratories) prepared according to the manufacturer's instructions. After $1 \mathrm{~h}$ of incubation, the sections were stained with diaminobenzidine (DAB) reagent (Vector Laboratories) and with methyl green counterstain. The stained sections were observed with a BX51 light microscope (Olympus, Tokyo, Japan). Neointima thickening was assessed using the intima/media ( $/ / \mathrm{M})$ thickness ratio measured from haematoxylin and eosin-stained arterial cross sections with a computer-based Image-Pro Morphometric System in a doubleblind manner. Four discontinuous sections from each vessel were measured in a Sprague-Dawley rat, whereas 6 rats were used in each experimental group [the control (distilled water, the sham-operated rats and the digoxin-treated rats].

Statistical analysis. Data are presented as the means \pm SEM. ANOVA and a paired or unpaired t-test were performed for statistical analysis where appropriate. A value of $\mathrm{P}<0.05$ was considered to indicate a statistically significant difference.

\section{Results}

Digoxin inhibits the proliferation of VSMCs induced by $P D G F-B B$. The VSMCs were pre-treated with various concentrations (10-500 $\mathrm{nmol} / \mathrm{l})$ of digoxin followed by stimulation with PDGF-BB $(25 \mu \mathrm{g} / \mathrm{l})$ for $24 \mathrm{~h}$. Digoxin inhibited the PDGF-BB-induced proliferation of VSMCs in a concentrationdependent manner (Fig. 1A and B). The number of cells was significantly increased following treatment with $25 \mu \mathrm{g} / \mathrm{l}$ PDGF-BB compared to the non-stimulated group. However, the cell numbers were significantly reduced following co-culture with 10-500 nM digoxin. In addition, MTT assay revealed the same inhibitory pattern on VSMC proliferation (Fig. 1B). The cells treated with digoxin $(10-500 \mathrm{nM})$ for $24 \mathrm{~h}$ in the absence of PDGF-BB showed no significant difference in viability compared with the untreated cells, suggesting that digoxin is not cytotoxic at the concentrations tested. Furthermore, re-endothelialization is a vital process for arterial injury repair. To exclude a cell cytotoxic effect of digoxin, we determined cell necrosis by trypan blue exclusion in the absence or presence of digoxin. We examined the effects of digoxin on endothelial cell viability. The HUVECs were incubated in the absence or presence of digoxin for $48 \mathrm{~h}$ before their viability was analyzed according to their ability to exclude trypan blue. Digoxin did not induce the necrosis of HUVECs at up to $48 \mathrm{~h}$ (Fig. 1C), and digoxin had no negative effect on VSMC viability (Fig. 1D). 
A

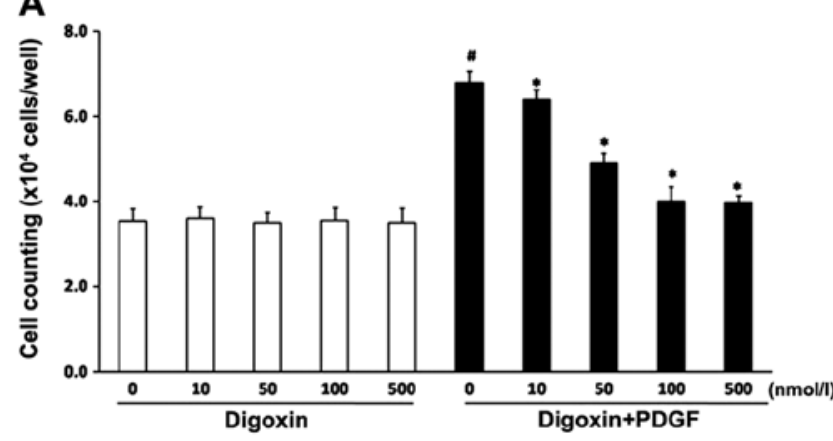

C

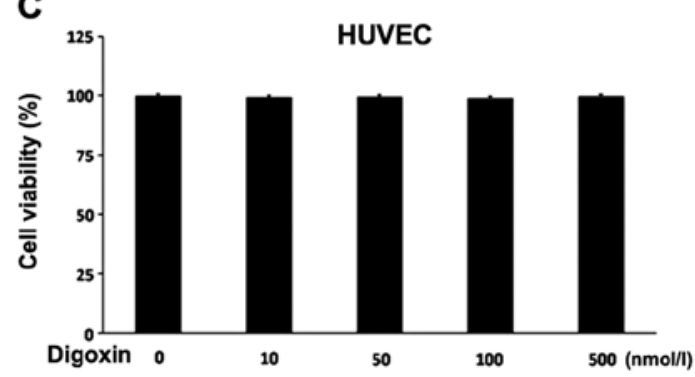

B

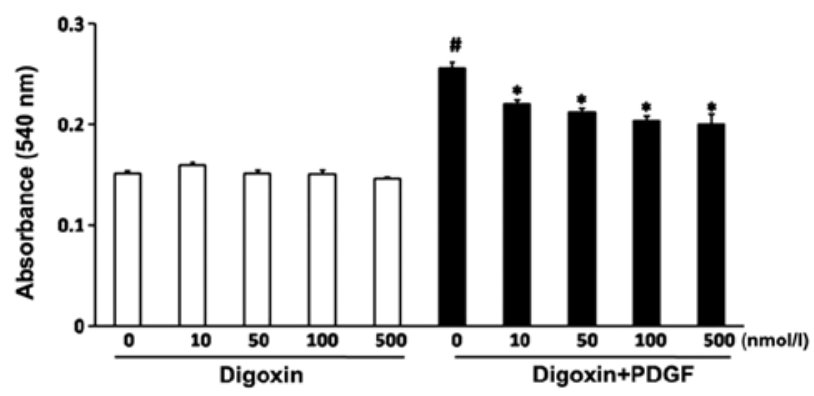

D

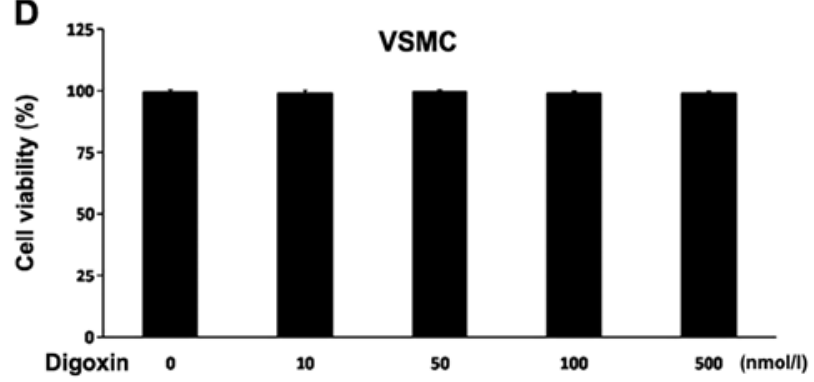

Figure 1. Digoxin prevents the proliferation of vascular smooth muscle cells (VSMCs) induced by platelet-derived growth factor (PDGF)-BB. VSMCs were pre-cultured in serum-free medium for $24 \mathrm{~h}$ and then treated with the indicated concentrations of digoxin ( 10 to $500 \mathrm{nM})$ for $24 \mathrm{~h}$ in the presence or absence of PDGF-BB $(25 \mu \mathrm{g} / \mathrm{l})$. (A) The cells were trypsinized with $0.1 \%$ trypsin-EDTA and counted using a hemocytometer under a microscope $\left({ }^{\sharp} \mathrm{P}<0.01 \mathrm{vs}\right.$. the control group; ${ }^{*} \mathrm{P}<0.05$ vs. treatment with PDGF-BB alone; $\mathrm{n}=6$ ). (B) The viability of VSMCs was detected by MTT assay. MTT reagent was added at 24 h followed by further incubation for $3 \mathrm{~h}$. Results are expressed as the mean OD540 \pm SEM of measurements from 4 different experiments ( ${ }^{\sharp} \mathrm{P}<0.01$ vs. the control group; ${ }^{*} \mathrm{P}<0.05$ vs. treatment with PDGF-BB alone; $\mathrm{n}=6$ ). (C) Human umbilical vein endothelial cells (HUVECs) were incubated in growth medium in the absence or presence of various concentrations of digoxin for $48 \mathrm{~h}$, and cell viability was evaluated by trypan blue exclusion (no signficant changes were observed vs. control group; $n=4)$. (D) VSMCs were incubated in growth medium in the absence or presence of different concentrations of digoxin for $48 \mathrm{~h}$, and cell viability was evaluated by counting the number of cells that excluded the trypan blue dye (no signficant changes were observed vs. control group; $\mathrm{n}=4$ ).

Digoxin inhibits the PDGF-BB-induced cell cycle progression of VSMCs. To elucidate the mechanisms responsible for the anti-proliferative effects of digoxin, the effects of digoxin on cell cycle progression were analyzed. The cells were preincubated in the presence or absence of digoxin in serum-free medium for $24 \mathrm{~h}$ and then stimulated with PDGF-BB $(25 \mu \mathrm{g} / \mathrm{l})$. After $24 \mathrm{~h}$, an individual nuclear DNA content is reflected as the fluorescence intensity of incorporated PI. As shown by flow cytometry, treatment with PDGF-BB alone significantly increased the percentage of cells in the $S$ phase while decreasing the G0/G1 cell population. By contrast, digoxin at a concentration of $100 \mathrm{nM}$ significantly increased the fraction of G0/G1 phase cells and decreased the number of VSMCs in the $\mathrm{S}$ phase, indicating that digoxin prevented cell cycle entry/ progression into the G0/G1 phase (Fig. 2). This result suggests that digoxin acts at the early stages of cell cycle progression.

Effects of digoxin on the PDGF-BB-induced expression of cell cycle-related proteins in VSMCs. Cell cycle progression is tightly regulated through specific CDK cyclin protein complexes (21). To elucidate the mechanisms responsible for digoxin-induced cell cycle arrest, the effects of digoxin on cell cycle events, such as CDK protein expression, were analyzed by western blot analysis. The expression of CDK4 and CDK6 was induced by PDGF-BB $(25 \mu \mathrm{g} / \mathrm{l})$, whereas treatment with digoxin $(100 \mathrm{nM})$ significantly decreased the expression of these molecules (Fig. 3A). Cyclin-CDK complexes are precisely regulated by cell cycle inhibitors that block their catalytic activity. One such inhibitor is p27Kip1, which inactivates the cyclin-CDK complexes in the G1 phase, leading to cell cycle arrest (22). Subsequently, we assessed the effects of digoxin on the induction of p27Kip1 expression. p27Kip1 was constitutively expressed in the serum-starved quiescent VSMCs and was downregulated by stimulation with PDGF-BB. By contrast, pre-treatment with digoxin partly restored p27Kip1 expression to levels that were comparable to those in the quiescent cells (Fig. 3).

Effects of digoxin on the regulation of smooth muscle cell contractile gene expression. To evaluate the phenotypic modulation of VSMCs by digoxin, western blot analysis was used to detect differentiated phenotype markers. VSMCs were precultured in serum-free medium for $24 \mathrm{~h}$ and then treated with digoxin $(100 \mathrm{nM})$ for $24 \mathrm{~h}$ followed by stimulation with or without PDGF-BB $(25 \mu \mathrm{g} / \mathrm{l})$ for $24 \mathrm{~h}$. PDGF-BB reduced the protein levels of SM22a, calponin and SM $\alpha$-actin (Fig. 4). Moreover, pre-treatment with digoxin partially blocked the suppressive effects of PDGF-BB, suggesting that digoxin contributes to maintaining the quiescent (differentiated) state of VSMCs.

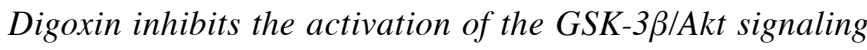
cascade induced by PDGF-BB in VSMCS. To further delineate the cellular and molecular mechanisms underlying the inhibition of PDGF-BB-induced VSMC growth by digoxin, 

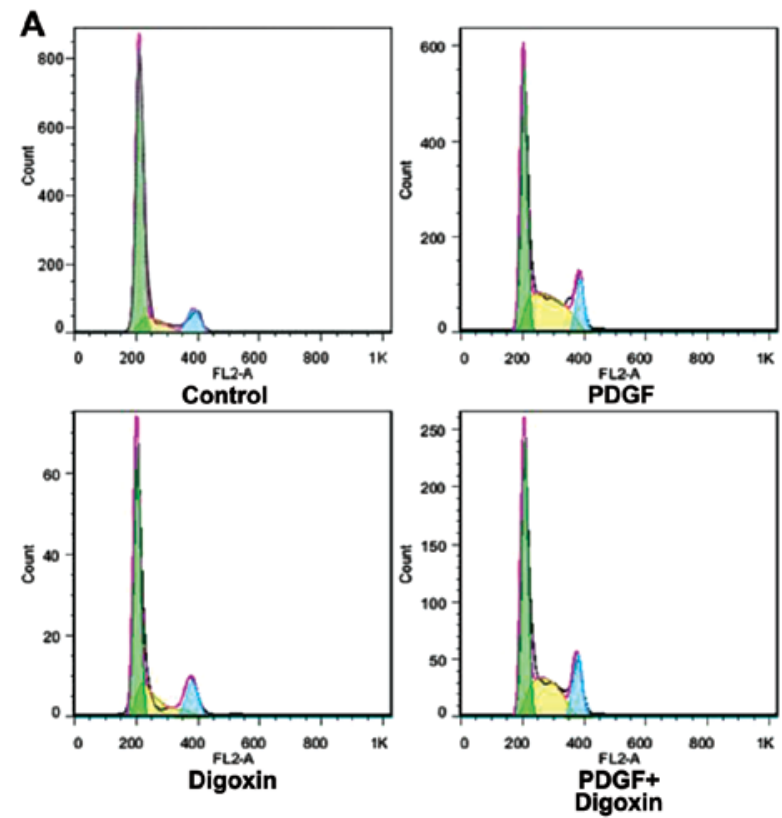

B

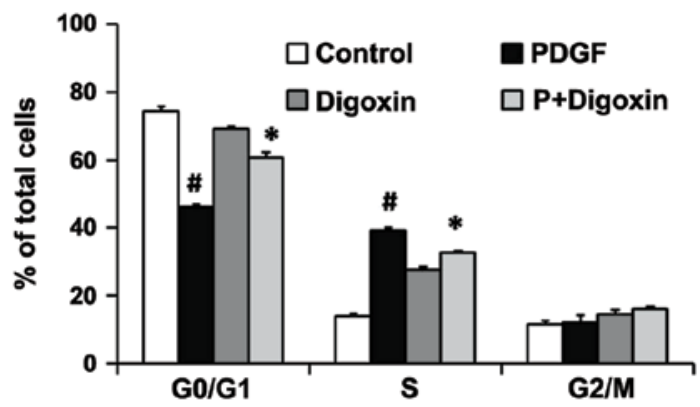

Figure 2. Digoxin inhibits platelet-derived growth factor (PDGF)-BB-induced cell cycle progression in vascular smooth muscle cells (VSMCs). The cells were preincubated in the presence or absence of digoxin $(100 \mathrm{nM})$ in serum-free medium for $24 \mathrm{~h}$ and then stimulated with PDGF-BB $(25 \mu \mathrm{g} / \mathrm{l})$. After $24 \mathrm{~h}$, the cell population in the G0/G1, S and G2/M phase was determined by flow cytometric analysis. (A) Representative cell cycle profiles are shown. (B) Quantification of VSMCs in the $\mathrm{G} 0 / \mathrm{G} 1, \mathrm{~S}$ and $\mathrm{G} 2 / \mathrm{M}$ phase as determined by flow cytometric evaluation ( ${ }^{*} \mathrm{P}<0.05$ vs. the control group; ${ }^{*} \mathrm{P}<0.05$ vs. treatment with $\mathrm{PDGF}-\mathrm{BB}$ alone; $\left.\mathrm{n}=3\right)$.

\section{A}
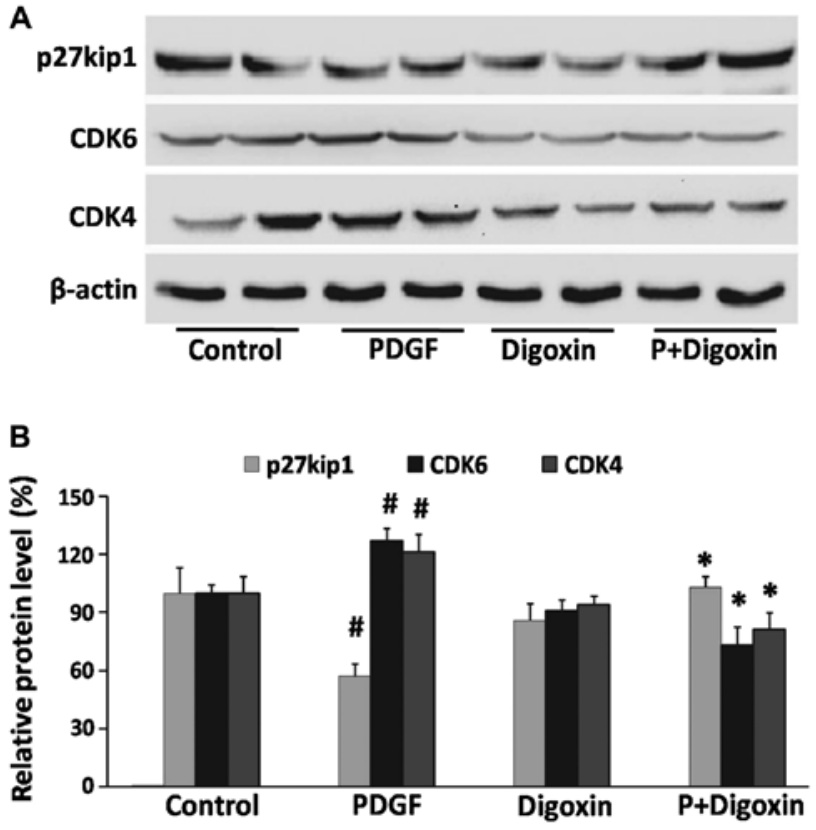

Figure 3. Effects of digoxin on platelet-derived growth factor (PDGF)-BBinduced cell cycle related-protein epxression in vascular smooth muscle cells (VSMCs). The cells were pre-incubated in the presence or absence of digoxin $(100 \mathrm{nM})$ in serum-free medium for $24 \mathrm{~h}$ and then stimulated with PDGF-BB $(25 \mu \mathrm{g} / \mathrm{l})$ for $24 \mathrm{~h}$. The expression levels of cell cycle regulatory proteins (p27Kip1, CDK6 and CDK4) was measured by western blot analysis. The results are expressed as relative values from 3 independent experiments. $\left({ }^{*} \mathrm{P}<0.05\right.$ vs. the control group; ${ }^{*} \mathrm{P}<0.05$ vs. treatment with PDGF alone; $\left.\mathrm{n}=4\right)$.
A

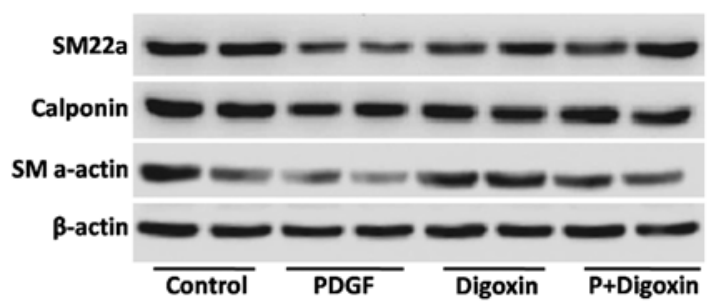

B

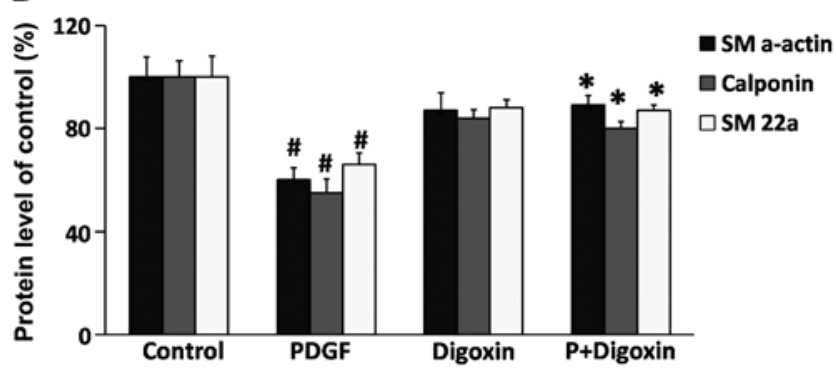

Figure 4. Effect of digoxin on the regulation of smooth muscle cell contractile profiles. Vascular smooth muscle cells (VSMCs) were pre-cultured in the serum-free medium for $24 \mathrm{~h}$ and then treated with the digoxin $(100 \mathrm{nM})$ for $24 \mathrm{~h}$ and then stimulated with platelet-derived growth factor (PDGF)-BB $(25 \mu \mathrm{g} / \mathrm{l})$ for $24 \mathrm{~h}$. (A) Protein levels of SM22a, calponin and SM $\alpha$-actin were determined by western blot analysis and quantified by densitometry. $\beta$-actin was used as an internal control. (B) Bar graphs showing the quantification of the western blots; results are expressed as percentages of the control. The results are expressed as relative values from 3 independent experiments. $\left({ }^{*} \mathrm{P}<0.05\right.$ vs. the control group; ${ }^{*} \mathrm{P}<0.05$ vs. treatment with $\mathrm{PDGF}$ alone; $\mathrm{n}=3$ ). the serum-starved VSMCs were stimulated with PDGF-BB for various periods of time in the absence or presence of didoxin (100 nM), and the phosphorylation status of ERK1/2, JNK and p38 MAPK, was measured by western blot analysis using antibodies that identify the active (phosphorylated) forms of these kinases. Our results revealed that PDGF-BB induced the rapid and sustained phosphorylation of ERK1/2, JNK and p38, without affecting their total levels. However, no changes were observed in the phosphorylated forms of ERK1/2, JNK and p38 when the cells were pre-treated with digoxin at the 
A

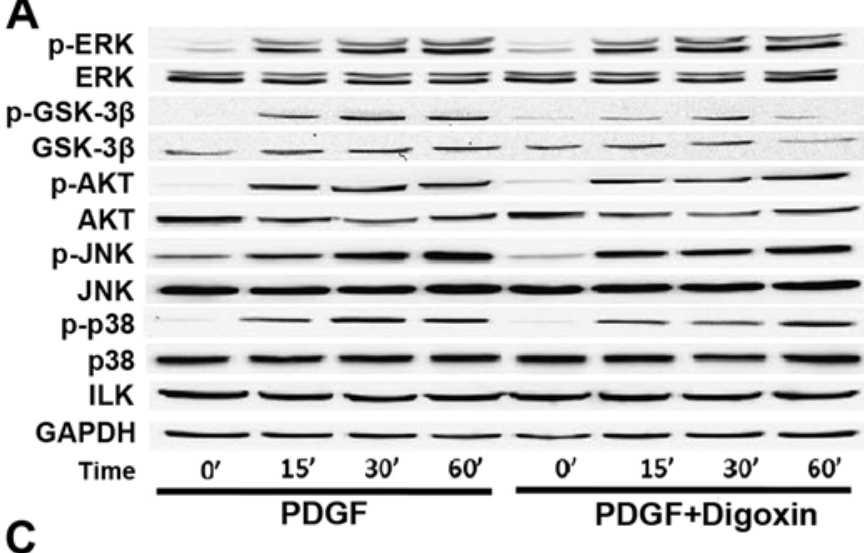

B

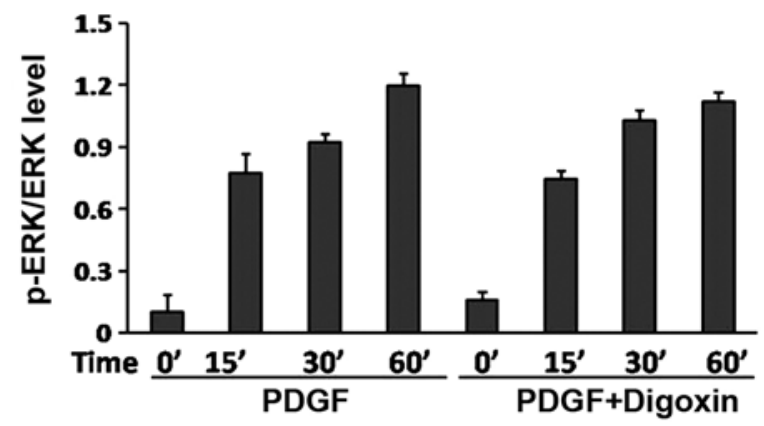

D
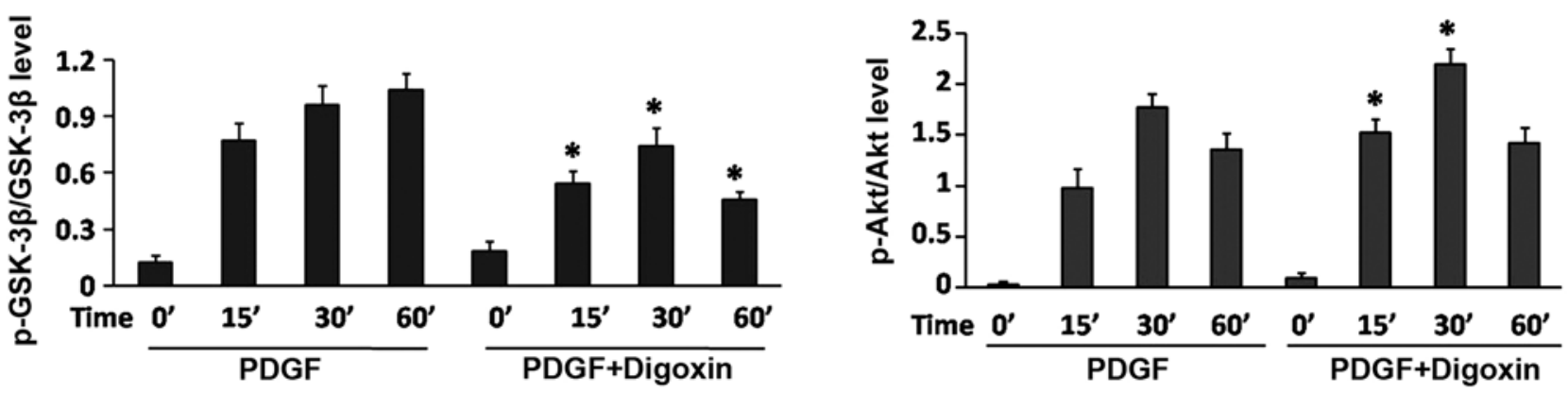

Figure 5. Digoxin inhibits the activation of glycogen synthase kinase (GSK)-3 $\beta$ induced by platelet-derived growth factor (PDGF)-BB and increases Akt signaling cascade in vascular smooth muscle cells (VSMCs). VSMCs were pre-cultured in the serum-free medium for $24 \mathrm{~h}$. The serum-starved VSMCs were then stimulated with PDGF-BB for the indicated periods of time in the absence or presence of didoxin (100 nM). The protein levels of p-ERK1/2, ERK1/2, p-GSK-3 $\beta$, GSK-3 $\beta$, p-Akt, Akt, JNK, p-JNK, p-p38, p38 and integrin linked kinase (ILK) were determined by western blot analysis. GAPDH was used as an internal control. (A) One representative image out of 4 independently performed experiments is shown. (B) Bar graphs showing the quantification of the western blots; results were expressed as percentage of the control ( $\mathrm{P}<0.05$ vs. treatment with PDGF alone; $\mathrm{n}=4)$.

indicated time points (Fig. 5A and B). Previous studies have also demonstrated that the GSK3 $3 /$ Akt signal transduction pathway is critically involved in VSMC proliferation and migration. Therefore, we evaluated the effects of digoxin on the PDGFinduced activation of the GSK3 $3 /$ Akt pathway. Our results revealed that PDGF-BB induced the rapid and sustained phosphorylation of GSK3 $\beta$ and Akt (Fig. 5A, C and D). However, the PDGF-BB-induced GSK3 $\beta$ phosphorylation was significantly impaired by digoxin in a time-dependent manner. However, the increased phosphorylation of Akt was even observed at $15 \mathrm{~min}$ after PDGF-BB and digoxin co-treatment, and was sustained for up to 30 min compared to stimulation with PDGF-BB alone as assessed by western blot analysis. These results suggest that digoxin reduces GSK-3 $\beta$ and increases Akt activity in PDGF-BB-stimulated VSMCs.

Digoxin activates the ILK signaling cascade and inhibits the activation of the GSK-3 $\beta$ signaling cascade induced by $P D G F-B B$ in VSMCs. ILK has been shown to be a critical effector in the PI3K-dependent signaling pathway that is downstream from both growth factor and integrin receptor activation (23). The stimulation of ILK results in the activation of Akt and the inhibition of GSK-3 $\beta$ (23). Thus, we further examined the effects of digoxin on the PDGF-BB-induced activation of the PI3K/ILK/GSK-3 $\beta$ signal transduction pathway in VSMCs. The VSMCs were pre-cultured in serum-free medium for $24 \mathrm{~h}$ and then stimulated with PDGF-BB for $48 \mathrm{~h}$ in the absence or presence of digoxin (100 nM). The protein levels of ILK, GSK-3 $\beta$ and Akt were determined by western blot analysis. Our results revealed that digoxin restored the expression of ILK which was suppressed by PDGF-BB and prevented the PDGF-BB-induced increase in GSK-3 $\beta$ expression without affecting the level of Akt in the cells treated with both PDGF-BB and digoxin (Fig. 6).

Digoxin inhibits PDGF-BB-induced cell migration through the PI3K/GSK-3 $\beta$ signaling cascade. The migration of smooth muscle cells from the media to the intimal region is another important component of vascular lesion formation (24). PDGF-BB initiates a multitude of biological effects through the activation of intracellular signal transduction pathways that contribute to VSMC migration (25). Thus, we examined the effects of digoxin on PDGF-BB-induced VSMC migration by Transwell assay which is used to assess chemotaxis. We examined whether digoxin plays a role in regulating VSMC migration. Treatment with PDGF-BB $(25 \mu \mathrm{g} / \mathrm{l})$ for $6 \mathrm{~h}$ increased the basal migration of the VSMCs by $>2$-fold (Fig. 7); however, compared to stimulation with PDGF-BB alone, a 30\% decrease in cell migration was observed in the cells treated with both PDGF-BB and digoxin. These results suggest that digoxin is a potent inhibitor of VSMC migration. Co-stimulation with LY294002, an inhibitor of PI3K, inactivated ILK/Akt and prevented the anti-migratory effects of digoxin in the VSMCs. However, pre-treatment with SB415286, a specific antagonist of GSK-3 $\beta$, resulted in a $>2$-fold decrease in the number of VSMCs moving across the membrane, compared to co-culture 

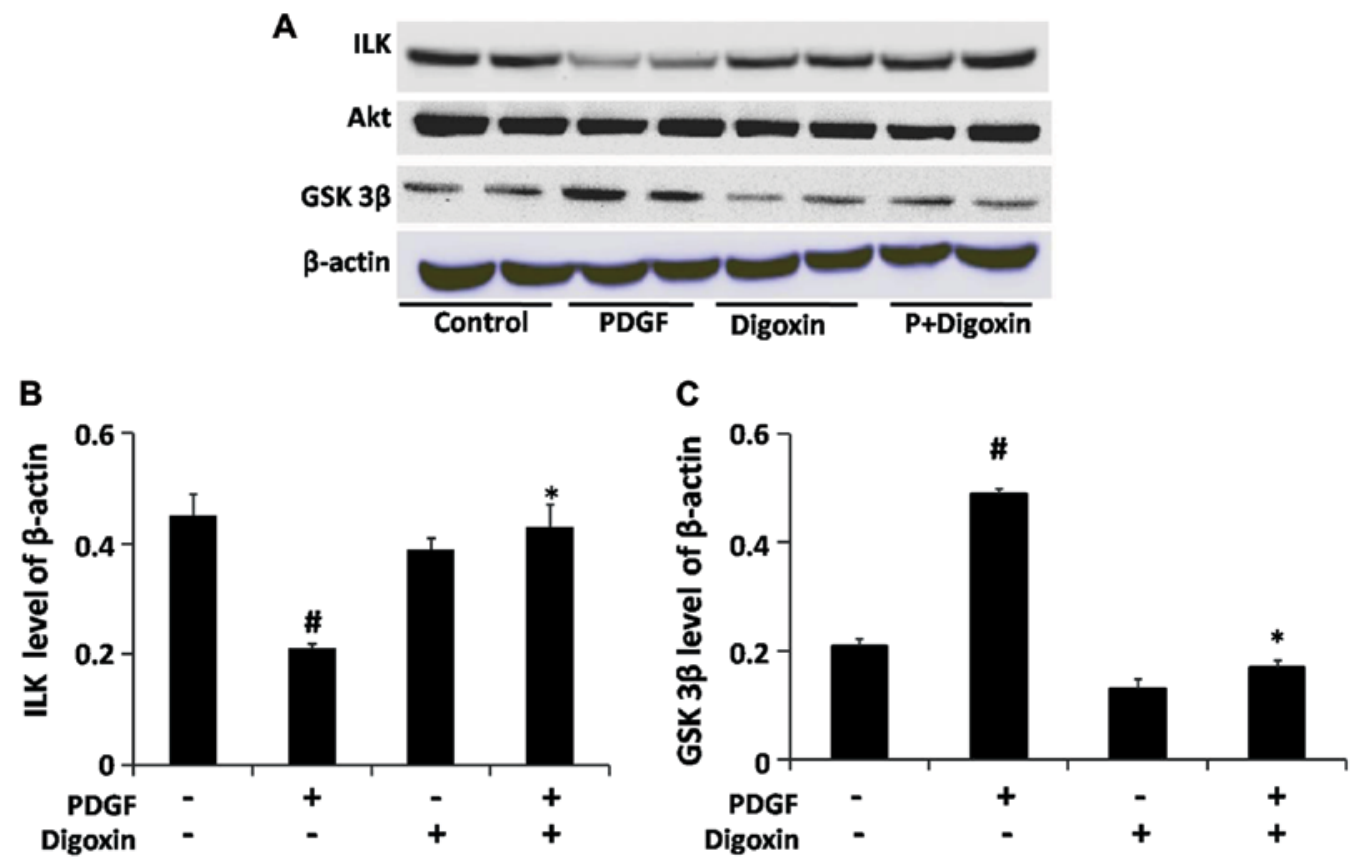

Figure 6. Digoxin increases integrin linked kinase (ILK) signaling and inhibits glycogen synthase kinase (GSK)-3 $\beta$ signaling activated by platelet-derived growth factor (PDGF)-BB in vascular smooth muscle cells (VSMCs). VSMCs were pre-cultured in the serum-free for $24 \mathrm{~h}$. The serum-starved VSMCs were then stimulated with PDGF-BB for $48 \mathrm{~h}$ in the absence or presence of digoxin (100 nM). Protein levels of ILK, GSK-3 $\beta$ and Akt were determined by western blot analysis. $\beta$-actin was used as an internal control. (A) One representative image out of 4 independently performed experiments is shown. (B) Bar graphs showing the quantification of the western blots; results were expressed as percentage of the control ( ${ }^{*} \mathrm{P}<0.05$ vs. control;" $\mathrm{P}<0.05$ vs. PDGF treatment with alone; $\left.\mathrm{n}=4\right)$ ).

with PDGF-BB and digoxin. These data demonstrate that digoxin inhibits PDGF-BB-induced cell migration through the PI3K/GSK-3 $\beta$ signaling cascade.

Digoxin inhibits the PDGF-BB induced expression of adhesion molecules and effects the expression of key proteins in the extracellular matrix (ECM) in VSMCs. To elucidate the molecular mechanisms responsible for the inhibitory effects of digoxin on VSMC migration, we examined the effects of digoxin on the migration regulatory proteins, ICAM-1 and VCAM-1. The stimulation of serum-starved VSMCs with PDGF-BB for $48 \mathrm{~h}$ in the absence of digoxin induced the upregulation of ICAM-1 and VCAM-1 protein expression (Fig. 8A and B). Treatment with $100 \mathrm{nM}$ digoxin resulted in an $\sim 60 \%$ decrease in the protein levels of ICAM-1 compared to the levels in the PDGF-BB-treated cells, and a $40 \%$ decrease was observed in the VCAM-1 level.

It is well known that MMPs degrade the ECM and promote VSMC migration from the media to the intimal region. The balance of MMPs and TIMPs is crucial to maintaining the dynamic equilibrium of the ECM (26). Therefore, we detected key factors in the ECM in VSMCs. Digoxin increased the protein expression of TIMP-1 and TIMP-2 which was suppressed by PDGF-BB in vitro (Fig. 8C). A similar result was obtained for the ratio of TIMP-2/MMP-2 and TIMP-1/MMP-9 (Fig. 8D). These findings suggest that digoxin inhibits the migration of VSMCs induced by PDGF-BB by suppressing the expression of migration-related proteins in these cells.

Effects of digoxin on neointima formation and cell proliferation in vivo. To investigate the role of digoxin in regulating VSMC proliferation in vivo, rat carotid arteries were harvested on day 14 following balloon injury, and an increased I/M thickness ratio of the carotid arteries was observed (Fig. 9A). The administration of digoxin injection $(1.0 \mathrm{mg} / \mathrm{kg} /$ day $)$ significantly decreased the I/M thickness ratio by $>45 \%$ compared with the injured control rats (Fig. 9B) and inhibited the injuryinduced increase in PCNA expression in the neointima of carotid arteries (Fig. 9C), and attenuated neointima formation. These results suggest that digoxin exerts an inhibitory effect on cell proliferation in vivo, and may be an effective agent for the prevention of restenosis following angioplasty.

\section{Discussion}

In the present study, to the best of our knowledge, we demonstrate for the first time that digoxin inhibits the PDGF-BB-induced phenotypic switching, proliferation and migration of VSMCs, and prevents neointima formation induced by balloon injury, at least in part through an increase in ILK/Akt signaling and a decrease in GSK-3 $\beta$ signaling.

Indeed, a number of studies have described the effects of cardiac glycosides, such as digoxin and digitoxin, on the regulation of cell attachment (27), the orientation of polarity (28), protein trafficking (29) and the induction of proliferation $(30,31)$. Overall, it is now clear that the ultimate response to cardiac glycoside treatment is dependent on the tissue, exposure time and dose (15). Numerous studies have confirmed the anti-proliferative effects of cardiac glycosides in several cancer cell lines, including breast (32), prostate (33), melanoma (34), pancreatic (35), lung (36), leukaemia (37), neuroblastoma (38) and renal adenocarcinoma (39). The exact mechanisms underlying these effects of cardiac glycosides are not yet fully understood. Our study demonstrated that the anti- 

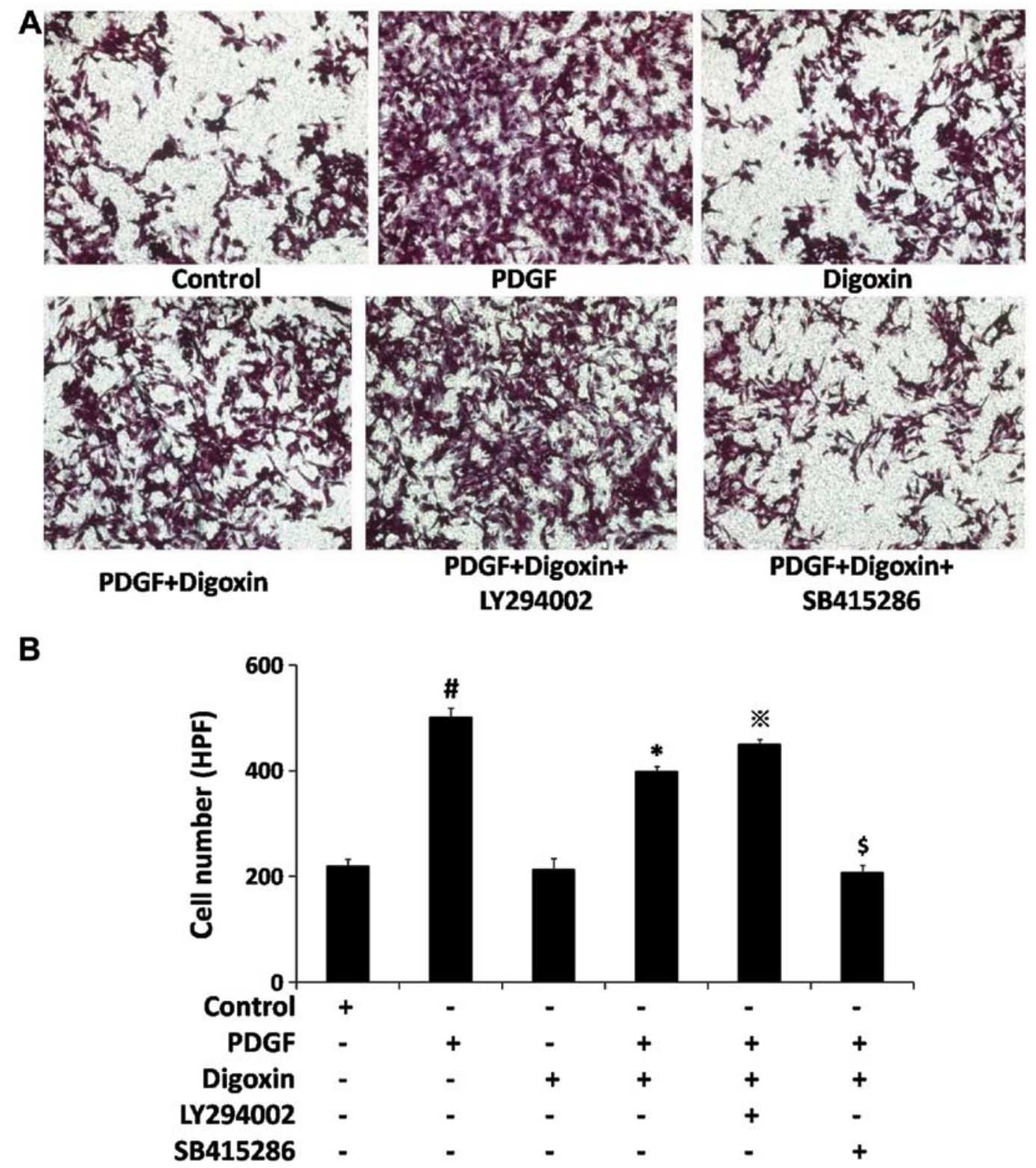

Figure 7. Digoxin inhibits platelet-derived growth factor (PDGF)-BB induced cell migration through the phosphoinositide 3-kinase (PI3K)/glycogen synthase kinase (GSK)-3 $\beta$ signaling cascade. Vascular smooth muscle cells (VSMCs) were pre-cultured in serum-free medium for $24 \mathrm{~h}$. The VSMCs were then cultured in a cell migration filter insert and stimulated with PDGF-BB $(25 \mu \mathrm{g} / \mathrm{l})$ for $6 \mathrm{~h}$ with or without digoxin treatment $(100 \mathrm{nmol} / \mathrm{l})$. (A) Transwell assay was used for the evaluation of the migration of VSMCs. Magnification, x200. (B) Cellular migration was determined by counting the cells that migrated through the pores. The results are presented as the means \pm SEM from 5 different experiments. ( ${ }^{\prime \prime} \mathrm{P}<0.05$ vs. control group; ${ }^{*} \mathrm{P}<0.05$ compared to $\mathrm{PDGF}-\mathrm{BB}$ alone group; and ${ }^{*}{ }^{\mathrm{S}} \mathrm{P}<0.05$ compared to PDGF + digoxin group).

proliferative activity of digoxin was associated with cell cycle arrest in the G0/G1 phase (Fig. 2). Cell cycle progression is a tightly regulated process that involves a complex cascade of events. A previous study indicated that pharmacological interventions to regulate the cell cycle inhibit VSMC proliferation and block neointimal hyperplasia (40). Therefore, the inhibition of VSMC cycle progression is considered an effective strategy for the control of VSMC proliferation. In this study, the fact that digoxin permitted the VSMCs to arrest in the G0/G1 phase suggests that the modulation of cell cycle regulatory proteins occurs following digoxin treatment. CDK4 and CDK6 are key mediators during the progression from the G0/G1 to the $\mathrm{S}$ phase of the cell cycle by forming complexes with cyclin A, $\mathrm{E}$ and D1 (41). Our data demonstrated that the expression of the cell cycle regulatory proteins, CDK4 and CDK6, decreased after the VSMCs were treated with digoxin, compared to stimulation with PDGF-BB alone (Fig. 3), indicating that cell cycle arrest in the G0/G1 phase is due to the downregulation of CDK/cyclin complex expression (4). The results from different research groups have also demonstrated that p27Kip1 inhibits the proliferation and migration of VSMCs $(42,43)$. In the present study, the digoxin-induced upregulation of p27Kip1 expression was consistent with the inhibitory effects of digoxin on VSMC migration. These results suggest that the effects of digoxin on p27Kip1 expression are involved in its inhibitory effects on VSMC proliferation and migration.

VSMCs can undergo transition from a quiescent, contractile/differentiated phenotype to a synthetic/dedifferentiated phenotype (44). To date, compelling evidence has indicated that PDGF-BB induces a profound suppression of VSMC marker 
A

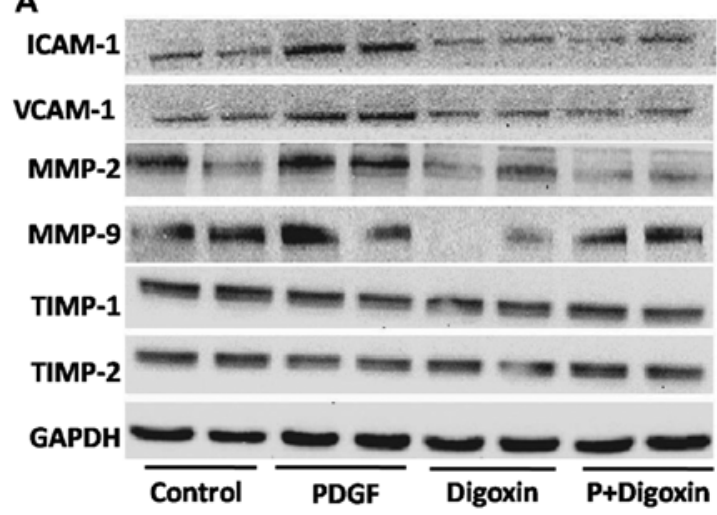

C

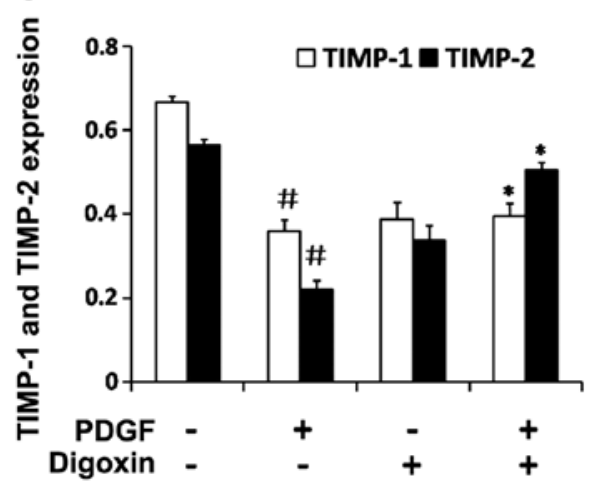

B

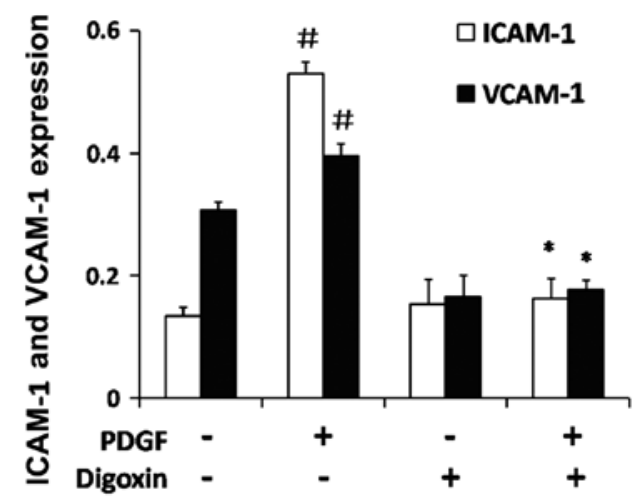

D

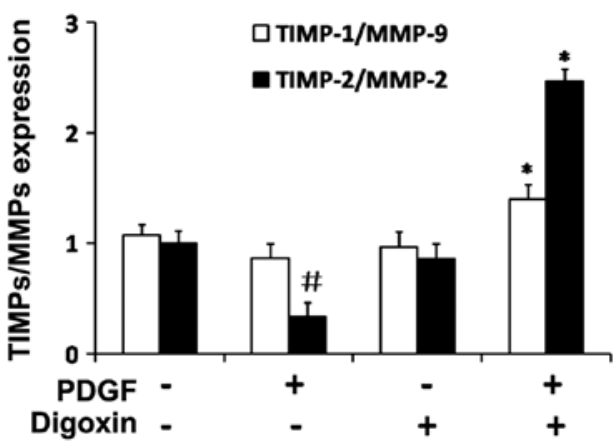

Figure 8. Digoxin inhibits platelet-derived growth factor (PDGF)-BB-induced adhesion molecule expression and effects the expression of key proteins in the extracelluar matrix in vascular smooth muscle cells (VSMCs). VSMCs were pre-cultured in serum-free medium for $24 \mathrm{~h}$. The serum-starved VSMCs were then stimulated with PDGF-BB for $48 \mathrm{~h}$ in the absence or presence of digoxin $(100 \mathrm{nM})$. The protein levels of intercellular adhesion molecule-1 (ICAM-1), vascular cell adhesion molecule-1 (VCAM-1), matrix metalloproteinase (MMP)-2, MMP-9, tissue inhibitor of metalloproteinase (TIMP)-1 and TIMP-2 were determined by western blot analysis. (A) One representative image out of 4 independently performed experiments is shown. (B-D) The graphs represented the relative level of these proteins for 4 independent experiment. ( $\mathrm{P}<0.05$ vs. the control group; ${ }^{*} \mathrm{P}<0.05$ vs. treatment with PDGF alone; $\mathrm{n}=3$ ).

A

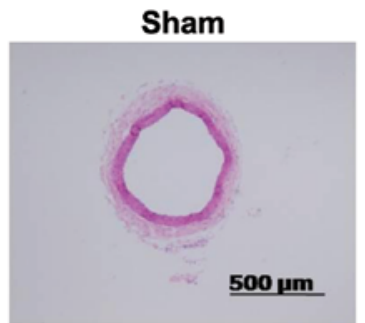

B

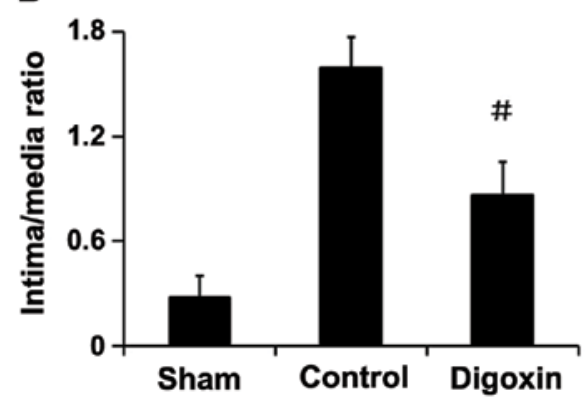

Control

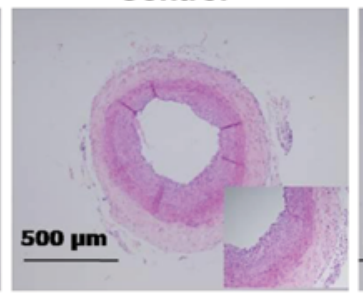

C

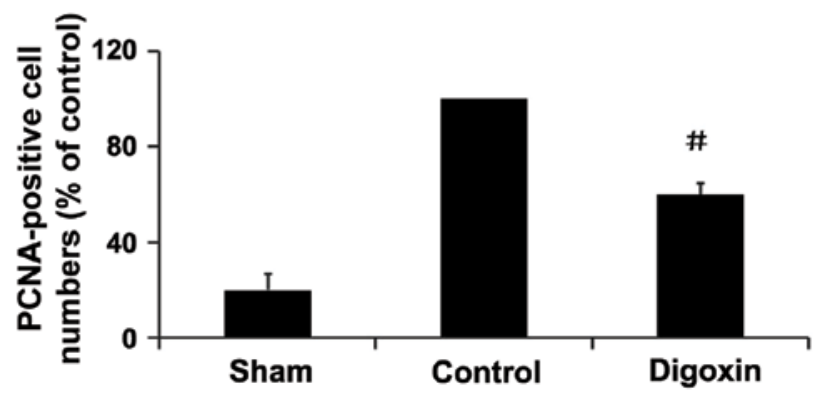

Figure 9. Digoxin inhibits neointima formation in vivo. The sections of rat carotid arteries were prepared on day 14 following balloon injury. (A) H\&E staining and (B) I/M thickness ratio analysis. (C) Quantification of PCNA-positive cells of carotid arteries of rats from either the control group or the digoxin-treated group ( $\mathrm{n}=6 ;{ }^{\#} \mathrm{P}<0.05$ vs. injured control treated with distilled water).

gene expression through multiple complementary pathways and plays a pivotal role during restenosis $(20,45)$. In accordance with previous studies, we observed that PDGF-BB decreased SM $\alpha$-actin, SM22a and calponin expression. Our in vitro 
experiments revealed that treatment with digoxin partly restored the expression of SM $\alpha$-actin, SM22a and calponin (Fig. 4), accompanied by a decrease in cell proliferation and migration. These results suggest that digoxin halts the change toward a deleterious VSMC phenotype induced by PDGF-BB, which in turn contributes to the suppression of neointima formation.

The mechanisms through which digoxin inhibits PDGF-BBinduced VSMC proliferation, migration and phenotypic modulation remain largely unclear. ILK is a widely expressed and evolutionally conserved component of cell-ECM adhesions. Activated ILK can directly phosphorylate Akt and GSK-3 $\beta$ (46); the phosphorylation of GSK-3 $\beta$ results in the inhibition of ILK. Yudowski et al (47) found that PI3K-Akt activation was an important part of the complex and was bound to a proline-rich region of the catalytic $\alpha$-subunit of $\mathrm{Na}^{+} / \mathrm{K}^{+}$-ATPase. In a similar manner, ouabain mediates proliferation through the nitric oxide-induced production of reactive oxygen species through the activation of the PI3K cascade (48). Our data demonstrated that digoxin restored the PDGF-BB induced inhibition of ILK expression and prevented the PDGF-BB-induced activation of GSK-3 $\beta$ without affecting the activation of the ERK1/2, JNK and p38 MAPK cascade. Additionally, digoxin prevented the PDGF-BB induced proliferation and migration of VSMCs accompanied by the activation of Akt. These findings are consistent with those of a previous study showing that digoxin prevents TNF- $\alpha$-induced apoptosis of endothelial cells accompanied by the activation of Akt through PI3K signaling (49).

It has previously been demonstrated that MMPs are rapidly activated following vascular injury in both atherosclerosis and angioplasty (50). MMPs degrade the ECM and promote VSMC migration from the media to the intimal region, and then initial VSMCs undergo proliferation, while migrating VSMCs secrete vast ECM products, including collagen I and III, progressively resulting in neointima formation (51). In this study, we found that digoxin significantly inhibited the expression of MMP-2 and MMP-9 induced by PDGF stimulation, and also had a significant effect on both TIMP-2 and TIMP-1 (the inhibitors of the MMPs). The ratios of MMP-2/TIMP-2 and MMP-9/ TIMP-1 imply that VSMC migration may be a disequilibrium process induced by PDGF-BB, and digoxin was able to balance the ratio to a normal condition. Therefore, the regulatory effects of digoxin on MMPs and TIMPs which are key factors in the ECM for VSMC migration, may contribute to its antimigratory effect on VSMCs.

In the present study, to determine whether our in vitro findings have any physiological relevance, we evaluated the effects of digoxin on neointima formation using an animal model of arterial balloon-injury. Although the doses of digoxin injection $(1.0 \mathrm{mg} / \mathrm{kg} / \mathrm{day})$ administered in this study are higher than those administered to humans, the comparison of the dosages between species is complicated by a number of factors. For example, on the basis of body weight versus surface area measurements, it has been suggested that a given dosage in humans requires a 12 -fold higher dose in rats (19). Drug metabolism can also vary considerably owing to differential mechanisms of uptake, clearance and/or degradation. With these caveats in mind, plasma digoxin levels measured in this study were at or below the therapeutic range used in digoxintreated patients $(0.5-2 \mathrm{ng} / \mathrm{ml})$. Our in vivo data indicated that digoxin significantly inhibited neointima formation, accom- panied by a decrease in cell proliferation following vascular injury in rats. These observations indicate the potential therapeutic application of digoxin in the treatment of cardiovascular diseases, such as restenosis.

\section{References}

1. Davis-Dusenbery BN, Wu C, Hata A and Sessa WC: Micromanaging vascular smooth muscle cell differentiation and phenotypic modulation. Arterioscler Thromb Vasc Biol 31: 2370-2377, 2011.

2. Goel SA, Guo LW, Liu B and Kent KC: Mechanisms of postintervention arterial remodelling. Cardiovasc Res 96: 363-371, 2012.

3. Weintraub WS: The pathophysiology and burden of restenosis. Am J Cardiol 100: 3K-9K, 2007.

4. Dzau VJ, Braun-Dullaeus RC and Sedding DG: Vascular proliferation and atherosclerosis: New perspectives and therapeutic strategies. Nat Med 8: 1249-1256, 2002.

5. Raines EW: PDGF and cardiovascular disease. Cytokine Growth Factor Rev 15: 237-254, 2004.

6. Ahmed A, Pitt B, Rahimtoola SH, Waagstein F, White M, Love TE and Braunwald E: Effects of digoxin at low serum concentrations on mortality and hospitalization in heart failure: A propensity-matched study of the DIG trial. Int J Cardiol 123: 138-146, 2008.

7. Pervaiz MH, Dickinson MG and Yamani M: Is digoxin a drug of the past? Cleve Clin J Med 73: 821-824, 826, 829-832 passim, 2006.

8. Newman RA, Yang P, Pawlus AD and Block KI: Cardiac glycosides as novel cancer therapeutic agents. Mol Interv 8: 36-49, 2008.

9. Prassas I and Diamandis EP: Novel therapeutic applications of cardiac glycosides. Nat Rev Drug Discov 7: 926-935, 2008.

10. Takara K, Takagi K, Tsujimoto M, Ohnishi N and Yokoyama T: Digoxin up-regulates multidrug resistance transporter (MDR1) mRNA and simultaneously down-regulates steroid xenobiotic receptor mRNA. Biochem Biophys Res Commun 306: 116-120, 2003.

11. Schoner W: Endogenous cardiac glycosides, a new class of steroid hormones. Eur J Biochem 269: 2440-2448, 2002.

12. Schoner W and Scheiner-Bobis G: Endogenous and exogenous cardiac glycosides and their mechanisms of action. Am J Cardiovasc Drugs 7: 173-189, 2007.

13. Schoner W and Scheiner-Bobis G: Endogenous and exogenous cardiac glycosides: Their roles in hypertension, salt metabolism, and cell growth. Am J Physiol Cell Physiol 293: C509-C536, 2007.

14. López-Lázaro M: Digitoxin as an anticancer agent with selectivity for cancer cells: Possible mechanisms involved. Expert Opin Ther Targets 11: 1043-1053, 2007.

15. Mijatovic T, Van Quaquebeke E, Delest B, Debeir O, Darro F and Kiss R: Cardiotonic steroids on the road to anti-cancer therapy. Biochim Biophys Acta 1776: 32-57, 2007.

16. Winnicka K, Bielawski K and Bielawska A: Cardiac glycosides in cancer research and cancer therapy. Acta Pol Pharm 63: 109-115, 2006.

17. Svensson A, Azarbayjani F, Bäckman U, Matsumoto T and Christofferson R: Digoxin inhibits neuroblastoma tumor growth in mice. Anticancer Res 25 (1A): 207-212, 2005.

18. Yoshida T, Zhang H, Iwase T, Shen J, Semenza GL and Campochiaro PA: Digoxin inhibits retinal ischemia-induced HIF-1alpha expression and ocular neovascularization. FASEB J 24: 1759-1767, 2010.

19. Abud EM, Maylor J, Undem C, Punjabi A,Zaiman AL, Myers AC, Sylvester JT, Semenza GL and Shimoda LA: Digoxin inhibits development of hypoxic pulmonary hypertension in mice. Proc Natl Acad Sci USA 109: 1239-1244, 2012.

20. Wang L, Zheng J, Du Y, Huang Y, Li J, Liu B, Liu CJ, Zhu Y, Gao Y, Xu Q, et al: Cartilage oligomeric matrix protein maintains the contractile phenotype of vascular smooth muscle cells by interacting with alpha(7)beta(1) integrin. Circ Res 106: 514-525, 2010.

21. Norbury C and Nurse P: Animal cell cycles and their control. Annu Rev Biochem 61: 441-470, 1992

22. Malumbres M and Barbacid M: To cycle or not to cycle: a critical decision in cancer. Nat Rev Cancer 1: 222-231, 2001. 
23. Qin J and Wu C: ILK: A pseudokinase in the center stage of cellmatrix adhesion and signaling. Curr Opin Cell Biol 24: 607-613, 2012.

24. Ross R: The pathogenesis of atherosclerosis: a perspective for the 1990s. Nature 362: 801-809, 1993.

25. Ferns GA, Raines EW, Sprugel KH, Motani AS, Reidy MA and Ross R: Inhibition of neointimal smooth muscle accumulation after angioplasty by an antibody to PDGF. Science 253 $1129-1132,1991$.

26. Glass CK and Witztum JL: Atherosclerosis. the road ahead. Cell 104: 503-516, 2001.

27. Contreras RG, Shoshani L, Flores-Maldonado C, Lázaro A and Cereijido M: Relationship between $\mathrm{Na}(+), \mathrm{K}(+)$-ATPase and cell attachment. J Cell Sci 112: 4223-4232, 1999.

28. Rajasekaran SA, Palmer LG, Moon SY, Peralta Soler A, Apodaca GL, Harper JF, Zheng Y and Rajasekaran AK: $\mathrm{Na}, \mathrm{K}-\mathrm{ATP}$ ase activity is required for formation of tight junctions, desmosomes, and induction of polarity in epithelial cells. Mol Biol Cell 12: 3717-3732, 2001.

29. Wang L, Wible BA, Wan X and Ficker E: Cardiac glycosides as novel inhibitors of human ether-a-go-go-related gene channel trafficking. J Pharmacol Exp Ther 320: 525-534, 2007.

30. Saunders R and Scheiner-Bobis G: Ouabain stimulates endothelin release and expression in human endothelial cells without inhibiting the sodium pump. Eur J Biochem 271: 1054-1062, 2004.

31. Abramowitz J, Dai C, Hirschi KK, Dmitrieva RI, Doris PA, Liu L and Allen JC: Ouabain- and marinobufagenin-induced proliferation of human umbilical vein smooth muscle cells and a rat vascular smooth muscle cell line, A7r5. Circulation 108 3048-3053, 2003.

32. Bielawski K, Winnicka $\mathrm{K}$ and Bielawska A: Inhibition of DNA topoisomerases I and II, and growth inhibition of breast cancer MCF-7 cells by ouabain, digoxin and proscillaridin A. Bio Pharm Bull 29: 1493-1497, 2006.

33. McConkey DJ, Lin Y, Nutt LK, Ozel HZ and Newman RA: Cardiac glycosides stimulate $\mathrm{Ca}^{2+}$ increases and apoptosis in androgen-independent, metastatic human prostate adenocarcinoma cells. Cancer Res 60: 3807-3812, 2000.

34. Newman RA, Yang P, Hittelman WN, Lu T, Ho DH, Ni D Chan D, Vijjeswarapu M, Cartwright C, Dixon S, et al: Oleandrin-mediated oxidative stress in human melanoma cells J Exp Ther Oncol 5: 167-181, 2006.

35. Newman RA, Kondo Y, Yokoyama T, Dixon S, Cartwright C, Chan D, Johansen M and Yang P: Autophagic cell death of human pancreatic tumor cells mediated by oleandrin, a lipidsoluble cardiac glycoside. Integr Cancer Ther 6: 354-364, 2007.

36. Frese S, Frese-Schaper M, Andres AC, Miescher D, Zumkehr B and Schmid RA: Cardiac glycosides initiate Apo2L/TRAILinduced apoptosis in non-small cell lung cancer cells by up-regulation of death receptors 4 and 5. Cancer Res 66: 5867-5874, 2006.

37. Hallböök H, Felth J, Eriksson A, Fryknäs M, Bohlin L, LarssonR and Gullbo J: Ex vivo activity of cardiac glycosides in acute leukaemia. PloS one 6: e15718, 2011.
38. Kulikov A, Eva A, Kirch U, Boldyrev A and Scheiner-Bobis G: Ouabain activates signaling pathways associated with cell death in human neuroblastoma. Biochim Biophys Acta 1768: 1691-1702, 2007.

39. López-Lázaro M, Pastor N, Azrak SS, Ayuso MJ, Austin CA and Cortés F: Digitoxin inhibits the growth of cancer cell lines at concentrations commonly found in cardiac patients. J Nat Prod 68: 1642-1645, 2005.

40. Gallo R, Padurean A, Jayaraman T, Marx S, Roque M, Adelman S, Chesebro J, Fallon J, Fuster V, Marks A, et al: Inhibition of intimal thickening after balloon angioplasty in porcine coronary arteries by targeting regulators of the cell cycle. Circulation 99: 2164-2170, 1999.

41. Sherr CJ and Roberts JM: CDK inhibitors: Positive and negative regulators of G1-phase progression. Genes Dev 13: 1501-1512, 1999.

42. Wang SH, Liang CJ, Weng YW, Chen YH, Hsu HY, Chien HF, Tsai JS, Tseng YC, Li CY and Chen YL: Ganoderma lucidum polysaccharides prevent platelet-derived growth factor-stimulated smooth muscle cell proliferation in vitro and neointimal hyperplasia in the endothelial-denuded artery in vivo. J Cell Physiol 227: 3063-3071, 2012.

43. Guan H, Gao L, Zhu L, Yan L, Fu M, Chen C, Dong X, Wang L, Huang $\mathrm{K}$ and Jiang $\mathrm{H}$ : Apigenin attenuates neointima formation via suppression of vascular smooth muscle cell phenotypic transformation. J Cell Biochem 113: 1198-1207, 2012.

44. Gomez D and Owens GK: Smooth muscle cell phenotypic switching in atherosclerosis. Cardiovasc Res 95: 156-164, 2012.

45. Wang Z, Wang DZ, Hockemeyer D, McAnally J, Nordheim A and Olson EN: Myocardin and ternary complex factors compete for SRF to control smooth muscle gene expression. Nature 428: 185-189, 2004

46. Persad S, Attwell S, Gray V, Mawji N, Deng JT, Leung D, Yan J, Sanghera J, Walsh MP and Dedhar S: Regulation of protein kinase B/Akt-serine 473 phosphorylation by integrin-linked kinase: Critical roles for kinase activity and amino acids arginine 211 and serine 343. J Biol Chem 276: 27462-27469, 2001.

47. Yudowski GA, Efendiev R, Pedemonte CH, Katz AI, Berggren PO and Bertorello AM: Phosphoinositide-3 kinase binds to a prolinerich motif in the $\mathrm{Na}^{+}, \mathrm{K}^{+}$-ATPase alpha subunit and regulates its trafficking. Proc Natl Acad Sci USA 97: 6556-6561, 2000.

48. Eva A, Kirch U and Scheiner-Bobis G: Signaling pathways involving the sodium pump stimulate NO production in endothelial cells. Biochim Biophys Acta 1758: 1809-1814, 2006.

49. Jagielska J, Salguero G, Schieffer B and Bavendiek U: Digitoxin elicits anti-inflammatory and vasoprotective properties in endothelial cells: Therapeutic implications for the treatment of atherosclerosis? Atherosclerosis 206: 390-396, 2009.

50. Chase AJ and Newby AC: Regulation of matrix metalloproteinase (matrixin) genes in blood vessels: A multi-step recruitment model for pathological remodelling. J Vasc Res 40: 329-343, 2003.

51. Johnson JL, Dwivedi A, Somerville M, George SJ and Newby AC: Matrix metalloproteinase (MMP)-3 activates MMP-9 mediated vascular smooth muscle cell migration and neointima formation in mice. Arterioscler Thromb Vasc Biol 31: e35-e44, 2011. 